\title{
Hemangioma orbitario, causa de proptosis y ptosis infantil
}

\section{Orbital haemangioma, cause of infantile proptosis and ptosis}

Javier Lacorzana ${ }^{1,2 *}$ y Marina Rubio-Prats ${ }^{2}$

${ }^{1}$ Departamento de Oftalmología, Hospital San Juan de la Cruz, Úbeda; ${ }^{2}$ Departamento de Oftalmología, Hospital Universitario Virgen de las Nieves, Granada. España

Paciente de 9 años que acude por leve ptosis en el ojo derecho (OD), con leve retracción del párpado inferior, ptosis con arruga cutánea alta, función del elevador no alterada y ligera proptosis en el OD (Fig. 1 A). Las medidas oculoplásticas fueron: apertura palpebral 10 y $11 \mathrm{~mm}$, distancia reflejo marginal 12.5 y $3 \mathrm{~mm}$, exposición escleral inferior 2 y $1 \mathrm{~mm}$, y exoftalmometría 15/14/base 100. El resto de la exploración mostró mejor agudeza visual corregida 0.9 Snellen en ambos ojos, ortotropía, cover/uncover $0^{\circ}$, versiones y ducciones normales, y fondos de ojos normales. La resonancia magnética reveló una lesión de $16 \times 14$ mm extraconal, adyacente al recto lateral, hiperintensa en T2 e hipointensa en T1, con marcada captación uniforme del contraste, muy sugestiva de hemangioma cavernoso (Figs. $1 \mathrm{~B}$ y 2). No se observaron alteraciones en el trayecto de los nervios ópticos.
La ptosis adquirida no es una presentación clínica frecuente asociada al hemangioma; sin embargo, la causa más frecuente de ptosis adquirida en la infancia es el hemangioma infantil ${ }^{1,2}$. En nuestro caso, la proptosis y la leve ptosis permitieron iniciar el estudio, siendo el tratamiento expectante, con buena evolución a día de hoy (Fig. 1 C).

\section{Financiamiento}

Los autores declaran no haber recibido financiamiento para este estudio.

\section{Conflicto de intereses}

Los autores declaran que no existen conflictos de intereses.

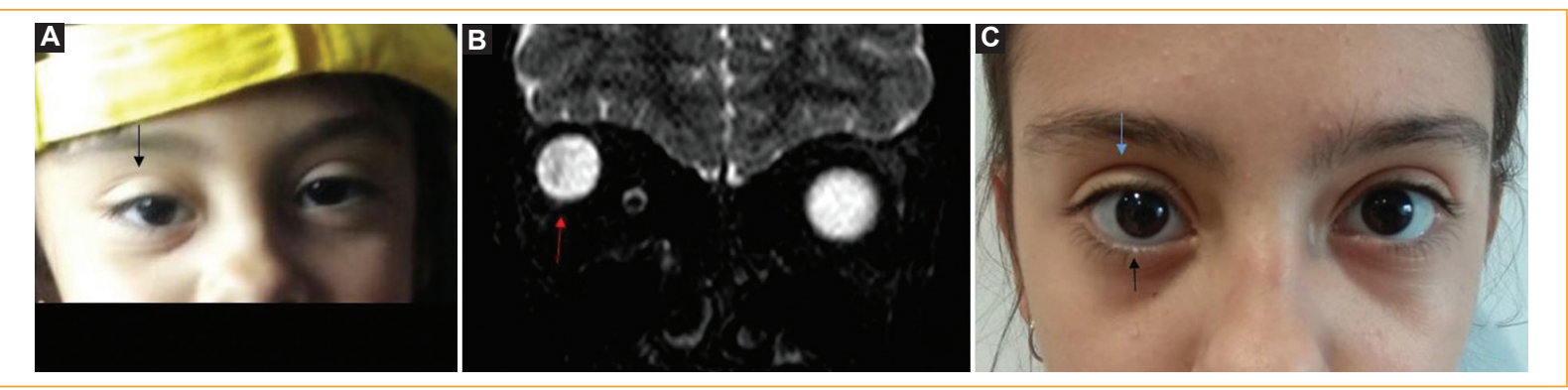

Figura 1. A: en la exploración se observan proptosis y ptosis del párpado superior con arruga cutánea alta (flecha) en el ojo derecho. B: la resonancia magnética muestra un hemangioma hiperintenso en T2 y con marcada captación de contraste (flecha). C: a los 2 años persiste una leve proptosis en el ojo derecho, retracción del párpado inferior (flecha negra) y ptosis casi resuelta debido a la regresión natural de la lesión (flecha azul).

Correspondencia:

*Javier Lacorzana

Avda. de las Fuerzas Armadas 2

Fecha de recepción: 10-01-2021

C.P. 18014, Granada, España

E-mail: javilacor@gmail.com

DOI: 10.24875/RMO.M21000197
Disponible en internet: $25-10-2021$

Rev Mex Oftalmol. (ahead of print)

www.rmo.com.mx

0187-4519/@ 2021 Sociedad Mexicana de Oftalmología. Publicado por Permanyer. Este es un artículo open access bajo la licencia CC BY-NC-ND (http://creativecommons.org/licenses/by-nc-nd/4.0/). 


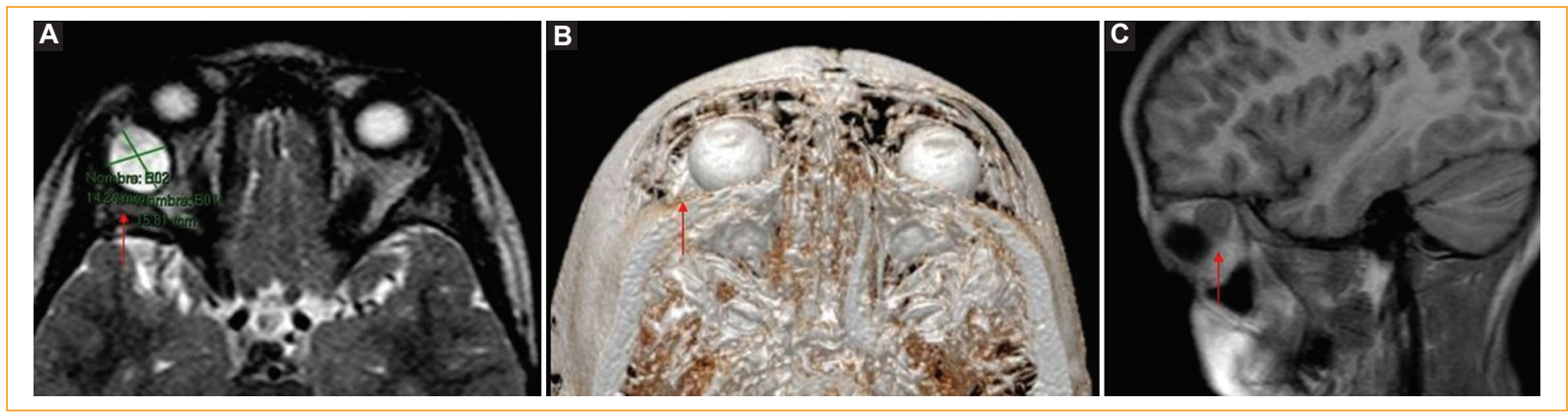

Figura 2. A: la resonancia magnética muestra una lesión hiperintensa en T2 y con marcada captación de contraste (flecha), de $16 \times 14 \mathrm{~mm}$, de extensión localizada por encima y sobre el músculo recto lateral del ojo derecho, sugestiva de hemangioma. B: reconstrucción tridimensional que muestra la lesión extraconal sin deformidad del globo ocular ni lesiones osteoclásticas adyacentes que pudiesen orientar a malignidad. C: en la resonancia magnética en T1 se observa la lesión hipointensa sin signos de malignidad.

\section{Responsabilidades éticas}

Protección de personas y animales. Los autores declaran que para esta investigación no se han realizado experimentos en seres humanos ni en animales.

Confidencialidad de los datos. Los autores declaran que han seguido los protocolos de su centro de trabajo sobre la publicación de datos de pacientes.

Derecho a la privacidad y consentimiento informado. Los autores han obtenido el consentimiento informado de los pacientes y/o sujetos referidos en el artículo. Este documento obra en poder del autor de correspondencia.

\section{Bibliografía}

1. López Almaraz R, López Gutiérrez JC, Belendez Bieler C, Herrero Hernández A, Mateos González ME, Ramírez Villar G. Tumores vasculares en la infancia. An Pediatr. 2010;72:143.e1-15.

2. Kralik SF, Haider KM, Lobo RR, Supakul N, Calloni SF, Soares BP. Orbital infantile hemangioma and rhabdomyosarcoma in children: differentiation using diffusion-weighted magnetic resonance imaging. J AAPOS. 2018;22:27-31. 